\title{
A prospective study of the contribution of migration to school drop-out rates amongst children made vulnerable by HIV/AIDS in eastern Zimbabwe
}

\author{
Constance Nyamukapa, Laura Robertson, Paradzai George Mushore, Simon Gregson
}

\section{Background}

Orphans and other children made vulnerable by HIV/AIDS have been found to be at increased risk of poor educational outcomes in sub-Saharan Africa [1-7]. In Zimbabwe, orphan status, particularly maternal orphanhood, has been associated with lower primary school completion rates $[8,9]$ and, amongst adolescent girls, lack of secondary school education [10], currently being out of school and poorer educational attainment [11].

In sub-Saharan Africa, orphans are usually cared for within the extended family [12]. Recent qualitative work [13, 14] from southern Africa has highlighted the potential negative impacts of AIDS orphans migrating to live with widely dispersed extended family members, including mistreatment by foster families and interruption of education.

In this paper, we use prospective data from a cohort of orphans and non-orphans in Manicaland, eastern Zimbabwe, to investigate whether children who recently migrated were at increased risk of dropping out of school.

\section{Methods}

Since 1998, five rounds of a population-based, open, prospective cohort study [15] have been conducted in twelve study sites in Manicaland province, eastern Zimbabwe - a predominantly rural area. At each round of this survey, a census of all households in the area is conducted, which enumerates all household members and collects basic demographic information, including the orphan status of all children less than 18 years old living in the household. Households that report deaths of adults aged 15-54 years during the inter-survey periods are approached and asked to complete a verbal autopsy questionnaire to ascertain the cause of death.

Three rounds of an embedded child cohort study were conducted in eight of the study sites between 2002 and 2006. All maternal and double orphans, one in five paternal orphans and one in fifty non-orphans aged under 18 years were identified in the second round of the main survey (2001/03) and were recruited to the embedded cohort study.

Additionally, all children under 18 years born to recently deceased adults that were identified in the second round verbal autopsy survey were recruited. Data were collected on various topics relating to child wellbeing, living arrangements and education.

At the third round of the embedded child cohort study, extra efforts were made to follow-up children who had migrated, both within and outside the study sites. For this reason, we used baseline data from round 2 and follow-up data from round 3 to investigate the association between migration and school dropout amongst children aged 6-18 years who were enrolled in school at round 2. Throughout this paper, to improve clarity, we will refer to data from the second round of the embedded child cohort study as baseline data and third round data as follow-up data.

We used multivariate logistic regression to investigate whether children who were enrolled in school at baseline and migrated between baseline and follow-up, were more likely to have dropped out of school at follow-up than children who were enrolled in school at baseline but did not move households between the study rounds. We adjusted for orphan status, relationship to primary caregiver (natural mother, natural father, grandparent, other close relative or other), type of location (subsistence farming area, agricultural estate, small town or roadside trading settlement), household wealth tertile (based on a simple summed score of household asset ownership - a method developed and validated using data collected in the main cohort study [16], age of the child and sex of the child. 


\section{Results}

763 children aged 6-18 years were enumerated at baseline and 645 (85\%) were followed up. 591/645 (92\%) of children aged 6-18 years, who were enumerated at baseline and follow-up, were enrolled in school at baseline and were therefore included in our main analysis. 11\% (50/467) of these children moved household between the two survey rounds and 9\% (56/590) had dropped out of school at follow-up.

Table 1 shows crude and adjusted risk factors for migration, between baseline and follow-up, amongst children aged 6-18 years. In the crude analyses, maternal orphans were at higher risk of migration compared to non-orphans. Children with any caregiver other than their natural mother were also at increased risk of migration, particularly those being cared for by their natural father. In the multivariate model, the strength of the associations between all types of orphanhood and migration were reduced and were no longer statistically significant. The effect of relationship to primary caregiver increased in the multivariate model, with children being cared for by their grandparents becoming more likely to have migrated between baseline and follow-up.

Table 2 shows the crude and adjusted risk factors for dropping out of school at follow-up amongst children aged 6-18 years who were in school at baseline. In the crude models, migration between baseline and follow-up is a strong risk factor for dropping out of school (AOR 4.49; 95\% CI 1.94-10.37) and this effect increases in the multivariate model (AOR 7.02; 95\% CI 2.76-17.87). Orphanhood and relationship to caregiver were not significantly associated with dropping out of school in the crude or adjusted models.

The majority of children who migrated moved to households outside their local area - 26\% (13/50) of children reported moving "locally" and 74\% (37/50) reported moving further afield. Figure 1 shows that children who reported migrating "locally" were more likely to drop out of school compared to children who did not migrate (AOR 3.22; 95\% CI 0.4921.08; $\mathrm{p}=0.222$ ), although this association was not statistically significant. Children who moved to more distant locations were significantly more likely to drop out of school compared with children who did not migrate between study rounds (OR 8.64; 95\% CI 3.10-24.08; $\mathrm{p}<0.001$ ).

Figure 1: Adjusted odds ratios comparing children aged 6-18 years who migrated locally, and those who migrated further away, with children who did not migrate between baseline and follow-up

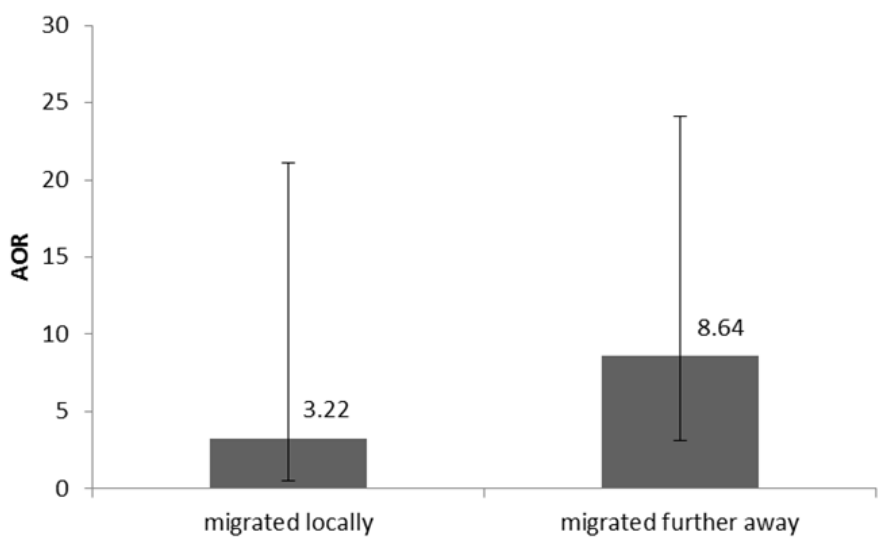

\section{Discussion}

Moving household was a significant risk factor for dropping out of school amongst children aged 6-18 years. Multivariate statistical models indicate that orphan status and relationship to primary caregiver are not independent risk factors for dropping out of school. This suggests that migration could mediate, at least to some extent, the risk of dropping out of school that has been associated previously with other demographic impacts of the HIV epidemic such as orphanhood. Interventions are required that improve household stability to reduce child migration and also that target recently migrated children to ensure rapid return to school. 
Table 1: Risk factors for migrating between baseline and follow-up rounds of the child cohort study amongst children aged 6-18 years at follow-up who were enrolled in school at baseline

\begin{tabular}{|c|c|c|c|c|c|c|c|c|}
\hline \multirow[b]{2}{*}{ RISK FACTOR } & \multirow[b]{2}{*}{$\%$ migrated } & \multirow[b]{2}{*}{$\mathbf{N}$} & \multicolumn{3}{|c|}{ Crude analysis* } & \multicolumn{3}{|c|}{ Adjusted analysis* } \\
\hline & & & $\mathrm{AOR}^{*}$ & $95 \% \mathrm{Cl}$ & p-value & $\mathrm{AOR}^{*}$ & $95 \% \mathrm{Cl}$ & p-value \\
\hline \multicolumn{9}{|l|}{ Orphan status } \\
\hline Non-orphans & $4.8 \%$ & 105 & - & - & - & - & - & - \\
\hline Maternal orphans & $18.9 \%$ & 53 & 4.23 & $1.32-13.59$ & 0.015 & 1.18 & $0.28-4.99$ & 0.820 \\
\hline Paternal orphans & $11.5 \%$ & 130 & 2.27 & $0.77-6.66$ & 0.137 & 1.97 & $0.62-6.29$ & 0.251 \\
\hline Double orphans & $11.4 \%$ & 140 & 2.25 & $0.78-6.54$ & 0.135 & 0.64 & $0.17-2.41$ & 0.509 \\
\hline Missing & $10.3 \%$ & 39 & 2.13 & $0.53-8.53$ & 0.287 & 0.79 & $0.16-3.96$ & 0.775 \\
\hline \multicolumn{9}{|l|}{ Relationship to primary caregiver } \\
\hline Natural mother & $5.7 \%$ & 159 & - & - & - & - & - & - \\
\hline Natural father & $18.2 \%$ & 22 & 3.88 & $1.04-14.48$ & 0.044 & 3.95 & $0.70-22.25$ & 0.120 \\
\hline Grandparent & $12.5 \%$ & 88 & 2.47 & $0.96-6.31$ & 0.060 & 3.81 & $1.17-12.47$ & 0.027 \\
\hline Other close relative & $17.5 \%$ & 103 & 3.49 & $1.45-8.41$ & 0.005 & 4.84 & $1.47-15.98$ & 0.010 \\
\hline Other & $27.3 \%$ & 11 & 4.47 & $0.90-22.35$ & 0.068 & 4.94 & $0.80-30.59$ & 0.086 \\
\hline Missing & $6.0 \%$ & 84 & 0.95 & $0.30-3.00$ & 0.927 & 1.11 & $0.33-3.73$ & 0.862 \\
\hline \multicolumn{9}{|l|}{ Socio-economic status } \\
\hline Least poor & $17.5 \%$ & 143 & - & - & - & - & - & - \\
\hline Poorer & $9.8 \%$ & 163 & 0.54 & $0.27-1.10$ & 0.091 & 0.56 & $0.26-1.21$ & 0.140 \\
\hline Poorest & $4.5 \%$ & 155 & 0.21 & $0.08-0.52$ & 0.001 & 0.23 & $0.09-0.60$ & 0.003 \\
\hline \multicolumn{9}{|l|}{ Location } \\
\hline Agricultural estates & $13.3 \%$ & 90 & - & - & - & - & - & - \\
\hline Small towns & $14.5 \%$ & 76 & 1.24 & $0.50-3.07$ & 0.647 & 0.93 & $0.34-2.53$ & 0.885 \\
\hline Roadside trading settlements & $10.0 \%$ & 140 & 0.76 & $0.33-1.77$ & 0.524 & 0.69 & $0.27-1.77$ & 0.444 \\
\hline Subsistence farming areas & $8.1 \%$ & 161 & 0.61 & $0.26-1.42$ & 0.247 & 0.53 & $0.21-1.33$ & 0.176 \\
\hline \multicolumn{9}{|l|}{ Age of child } \\
\hline $6-8$ years & $10.9 \%$ & 55 & - & - & - & - & - & - \\
\hline $9-11$ years & $8.3 \%$ & 120 & 0.73 & $0.25-2.17$ & 0.574 & 0.67 & $0.20-2.25$ & 0.516 \\
\hline $12-14$ years & $8.0 \%$ & 137 & 0.74 & $0.26-2.12$ & 0.571 & 0.54 & $0.16-1.80$ & 0.316 \\
\hline $15-16$ years & $11.4 \%$ & 88 & 1.00 & $0.34-2.99$ & 0.992 & 0.56 & $0.16-1.99$ & 0.368 \\
\hline $17-18$ years & $20.0 \%$ & 65 & 2.14 & $0.74-6.22$ & 0.162 & 1.46 & $0.41-5.18$ & 0.560 \\
\hline \multicolumn{9}{|l|}{ Sex of child } \\
\hline Male & $8.4 \%$ & 251 & - & - & - & - & - & - \\
\hline Female & $13.4 \%$ & 216 & 1.85 & $1.00-3.42$ & 0.048 & 2.26 & $1.16-4.40$ & 0.016 \\
\hline
\end{tabular}




\begin{tabular}{|c|c|c|c|c|c|c|c|c|c|c|c|}
\hline \multirow[b]{2}{*}{ RISK FACTOR } & \multirow[b]{2}{*}{$\%$ dropped out } & \multirow[b]{2}{*}{$\mathbf{N}$} & \multicolumn{3}{|c|}{ Crude analysis* } & \multicolumn{3}{|c|}{$\begin{array}{l}\text { Adjusted analysis (excluding } \\
\text { recent migration)* }\end{array}$} & \multicolumn{3}{|c|}{$\begin{array}{l}\text { Adjusted analysis (including } \\
\text { recent migration)* }\end{array}$} \\
\hline & & & OR & $95 \% \mathrm{Cl}$ & p-value & OR & $95 \% \mathrm{Cl}$ & p-value & OR & $95 \% \mathrm{Cl}$ & p-value \\
\hline \multicolumn{12}{|l|}{ Migrated between $\mathrm{R} 2$ and $\mathrm{R} 3$ ? } \\
\hline No & $7.7 \%$ & 416 & - & - & - & - & - & - & - & - & - \\
\hline Yes & $30.0 \%$ & 50 & 4.49 & $1.94-10.37$ & $<0.001$ & - & - & - & 7.02 & $2.76-17.87$ & $<0.001$ \\
\hline \multicolumn{12}{|l|}{ Orphan status } \\
\hline Non-orphans & $9.4 \%$ & 117 & - & - & - & - & - & - & - & - & - \\
\hline Maternal orphans & $8.0 \%$ & 75 & 0.54 & $0.17-1.73$ & 0.298 & 0.67 & $0.14-3.22$ & 0.619 & 0.80 & $0.14-4.53$ & 0.805 \\
\hline Paternal orphans & $10.6 \%$ & 151 & 0.92 & $0.36-2.32$ & 0.855 & 0.90 & $0.34-2.34$ & 0.822 & 0.49 & $0.17-1.42$ & 0.189 \\
\hline Double orphans & $9.2 \%$ & 196 & 0.62 & $0.25-1.54$ & 0.307 & 1.02 & $0.29-3.59$ & 0.978 & 0.79 & $0.18-3.51$ & 0.759 \\
\hline Missing & $9.8 \%$ & 51 & 0.67 & $0.19-2.43$ & 0.543 & 1.21 & $0.26-5.69$ & 0.814 & 1.46 & $0.25-8.56$ & 0.675 \\
\hline \multicolumn{12}{|l|}{ Relationship to primary caregiver } \\
\hline Natural mother & $11.8 \%$ & 170 & - & - & - & - & - & - & - & - & - \\
\hline Natural father & $10.3 \%$ & 29 & 0.87 & $0.21-3.64$ & 0.846 & 1.43 & $0.21-9.85$ & 0.715 & 0.98 & $0.11-8.76$ & 0.986 \\
\hline Grand parent & $5.2 \%$ & 136 & 0.41 & $0.15-1.09$ & 0.074 & 0.35 & $0.09-1.31$ & 0.120 & 0.38 & $0.08-1.75$ & 0.213 \\
\hline Other close relative & $10.8 \%$ & 139 & 0.46 & $0.20-1.06$ & 0.068 & 0.49 & $0.14-1.72$ & 0.265 & 0.29 & $0.06-1.35$ & 0.113 \\
\hline Other & $33.3 \%$ & 12 & 0.61 & $0.15-2.60$ & 0.508 & 0.71 & $0.13-3.82$ & 0.686 & 0.57 & $0.08-3.92$ & 0.567 \\
\hline Missing & $6.7 \%$ & 104 & 0.37 & $0.14-1.01$ & 0.053 & 0.42 & $0.14-1.28$ & 0.126 & 0.42 & $0.12-1.52$ & 0.186 \\
\hline \multicolumn{12}{|l|}{ Socio-economic status } \\
\hline Least poor & $9.7 \%$ & 185 & - & - & - & - & - & - & - & - & - \\
\hline Poorer & $12.4 \%$ & 202 & 1.94 & $0.93-4.02$ & 0.076 & 1.98 & $0.90-4.35$ & 0.088 & 3.33 & $1.27-8.73$ & 0.014 \\
\hline Poorest & $6.6 \%$ & 196 & 1.07 & $0.46-2.47$ & 0.879 & 1.01 & $0.42-2.45$ & 0.982 & 1.70 & $0.57-5.07$ & 0.338 \\
\hline \multicolumn{12}{|l|}{ Location } \\
\hline Agricultural estates & $7.1 \%$ & 113 & - & - & - & - & - & - & - & - & - \\
\hline Small towns & $11.0 \%$ & 91 & 2.25 & $0.77-6.59$ & 0.139 & 2.46 & $0.79-7.72$ & 0.122 & 2.02 & $0.56-7.26$ & 0.281 \\
\hline Roadside trading settlements & $11.7 \%$ & 180 & 2.15 & $0.85-5.42$ & 0.106 & 2.07 & $0.77-5.51$ & 0.147 & 2.32 & $0.79-6.78$ & 0.124 \\
\hline Subsistence farming areas & $8.3 \%$ & 206 & 1.76 & $0.68-4.55$ & 0.240 & 1.72 & $0.64-4.62$ & 0.282 & 1.20 & $0.39-3.72$ & 0.749 \\
\hline \multicolumn{12}{|l|}{ Age of child } \\
\hline $6-8$ years & $4.6 \%$ & 66 & - & - & - & - & - & - & - & - & - \\
\hline $9-11$ years & $0.7 \%$ & 145 & 0.14 & $0.01-1.35$ & 0.088 & 0.14 & 1.3 & 0.090 & 0.14 & $0.01-1.49$ & 0.103 \\
\hline $12-14$ years & $3.8 \%$ & 183 & 0.85 & $0.21-3.39$ & 0.814 & 0.86 & $0.22-4.59$ & 0.839 & 1.02 & $0.22-4.79$ & 0.981 \\
\hline $15-16$ years & $12.0 \%$ & 108 & 2.93 & $0.79-10.78$ & 0.107 & 3.17 & $0.75-13.89$ & 0.097 & 3.61 & $0.80-16.21$ & 0.094 \\
\hline $17-18$ years & $37.7 \%$ & 85 & 13.15 & $3.74-46.20$ & $<0.001$ & 15.35 & $4.47-78.28$ & $<0.001$ & 18.89 & $4.28-83.29$ & $<0.001$ \\
\hline
\end{tabular}

\section{Sex of child}

Male

$10.0 \% \quad 310$

Female

$8.9 \% \quad 280$

$1.16 \quad 0.62-2.15 \quad 0.649$

$1.05 \quad 0.50-2.20 \quad 0.904$

$1.07 \quad 0.51-2.26 \quad 0.861$

*The crude logistic regression model adjusts for age and sex of the child at follow-up and location at baseline; the adjusted models adjust for all variables, except migration status, which is excluded in the second model, presented here, but is included in the third model.

1. Bicego, G., S. Rutstein, and K. Johnson, Dimensions of the emerging orphan crisis in sub-Saharan Africa. Soc Sci Med, 2003. 56(6): p. 1235-47.

2. $\quad$ Monasch, R. and J.T. Boerma, Orphanhood and childcare patterns in sub-Saharan Africa: an analysis of national surveys from 40 countries. Aids, 2004. 18 Suppl 2: p. S55-65.

Beegle, K., J. De Weerdt, and S. Dercon, The intergenerational impact of the African orphans crisis: a cohort study from an HIV/AIDS affected area. Int J Epidemiol, 2009. 38(2): p. 561-8.

Parikh, A., et al., Exploring the Cinderella myth: intrahousehold differences in child wellbeing between orphans and non-orphans in Amajuba District, South Africa. Aids, 2007.

21 Suppl 7: p. S95-S103.

Timaeus, I.M. and T. Boler, Father figures: the progress at school of orphans in South Africa. Aids, 2007. 21 Suppl 7: p. S83-93.

Case, A. and C. Ardington, The impact of parental death on school outcomes: longitudinal evidence from South Africa. Demography, 2006. 43(3): p. 401-20.

Case, A., C. Paxson, and J. Ableidinger, Orphans in Africa: parental death, poverty, and school enrollment. Demography, 2004. 41(3): p. 483-508.

Nyamukapa, C., G. Foster, and S. Gregson, Orphans' household circumstances and access to education in a maturing HIV epidemic in eastern Zimbabwe. Journal of Social Development in Africa, 2003. 18(2): p. 7-32.

9. $\quad$ Nyamukapa, C. and S. Gregson, Extended family's and women's roles in safeguarding orphans' education in AIDS-afflicted rural Zimbabwe. Soc Sci Med, 2005. 60(10): p. 215567.

Gregson, S., et al., HIV infection and reproductive health in teenage women orphaned and made vulnerable by AIDS in Zimbabwe. AIDS Care, 2005. 17(7): p. 785-94.

Birdthistle, I., et al., Is education the link between orphanhood and HIV/HSV-2 risk among female adolescents in urban Zimbabwe? Soc Sci Med, 2009. 68(10): p. 1810-8.

Foster, G. and J. Williamson, A review of current literature on the impact of HIV/AIDS on children in sub-Saharan Africa. Aids, 2000. 14 Suppl 3: p. S275-84.

Ansell, N. and L. Young, Enabling households to support successful migration of AIDS orphans in southern Africa. AIDS Care, 2004. 16(1): p. 3-10.

Young, L. and N. Ansell, Young AIDS migrants in Southern Africa: policy implications for empowering children. AIDS Care, 2003. 15(3): p. 337-45.

Gregson, S., et al., HIV decline associated with behavior change in eastern Zimbabwe. Science, 2006. 311(5761): p. 664-6.

Lopman, B., et al., HIV incidence and poverty in Manicaland, Zimbabwe: is HIV becoming a disease of the poor? Aids, 2007. 21 Suppl 7: p. S57-66. 